Published in final edited form as:

J Am Chem Soc. 2002 December 04; 124(48): 14290-14291.

\title{
Preparation and Characterization of Porphyrin Nanoparticles
}

\author{
Xianchang Gong ${ }^{\star}, \dagger$, Tatjana Milic ${ }^{\ddagger}$, Chang Xu§, James D. Batteas ${ }^{\S}$, and Charles Michael \\ Drain $\ddagger$ \\ †Kava Technology, Inc. 65-16 Utopia Parkway, Fresh Meadows, New York 11365, Department of \\ Chemistry \\ ‡Hunter College of the City University of New York, 695 Park Avenue, New York, New York 10021 \\ $\S$ Department of Chemistry, College of Staten Island of the City University of New York, 2800 \\ Victory Boulevard, Staten Island, New York 10314
}

Porphyrins are a class of organic molecules with a macrocyclic tetrapyrrole core and different substituents. Porphyrins have remarkable photo-, catalytic-, electro-, and biochemical properties. ${ }^{1}$ They are extensively used in self-assembling processes to prepare monolayers and thin films. ${ }^{2,3}$ Multiporphyrin arrays are prepared both by organic synthesis and self-assembling techniques, ${ }^{1-4}$ and self-organized nanomaterials (radius $\approx 3 \mathrm{~nm}$ ) composed of porphyrins have also been prepared. ${ }^{4}$

The properties of many nanoscaled particles are substantially different than those of bulk materials composed of the same atoms or molecules. ${ }^{5}$ Nanometer-scale particles composed of metals, metal oxides, and other inorganic materials have been reported ${ }^{5}$ as have a few composed of organic molecules. ${ }^{6-12}$ Organic molecules also are used in self-assembling processes to prepare "soft" nanostructures such as spheres and tubes. ${ }^{2,3}$ Thus, nanoscaled particles composed of porphyrins are expected to have chemical activities significantly different from those of the free porphyrins or of those immobilized onto/into supports. Porphyrin nanoparticles are promising components of advanced materials because of the rich photochemistry, stability, and proven catalytic activity. ${ }^{1}$ In analogy to inorganic and other organic nanoparticles, it is expected that nanoparticles of porphyrins will have unique photonic properties not obtainable by larger-scaled materials containing the macrocycle, or by the molecules themselves. ${ }^{4}$ We report the formation of nanoparticles of catalytic porphyrins with enhanced stability and catalytic rate because of the structure of the aggregate and the greater surface area.

Here we report the first synthesis and characterization of porphyrin nanoparticles that are neither self-assembled by designed intermolecular interactions nor encapsulated in an external matrix. Porphyrin nanoparticles were prepared using mixing solvent techniques. ${ }^{7-12}$ (Polyetheylene)glycol (PEG) derivatives have been widely used in nanoparticle preparations to prevent agglomeration and precipitation of amorphous solids, such as for CdS. ${ }^{13} \mathrm{PEG}$ was

\footnotetext{
*To whom correspondence should be addressed. xianchanggong@email.msn.com.

Supporting Information Available: Preparation methods, DLS histograms, UV-vis, and AFM data for porphyrin nanoparticles in Table 1. (PDF) This material is available free of charge via the Internet at http://pubs.acs.org.
} 
used in experiments to prepare nanoparticles composed of meso-substituted tetraphenylporphyrins, Table 1 . The procedure to prepare nanoparticles composed of hydrophilic porphyrin $\mathrm{Fe}(\mathrm{III}) \mathbf{1}$ was to dissolve $0.6-3 \mathrm{mg}$ of porphyrin in $0.035-0.2 \mathrm{~mL}$ of water, followed by rapid addition of $5 \mathrm{~mL}$ of $\mathrm{CH}_{3} \mathrm{CN}$. For nanoparticles composed of hydrophobic/amphipathic porphyrins, $50 \mu \mathrm{L}$ of (triethyleneglycol)monomethyl ether was mixed into a $0.4 \mathrm{~mL}(0.28-1.2 \mathrm{mM})$ solution of the porphyrin in DMSO, and then $5 \mathrm{~mL}$ of water was added rapidly. In cases where DMSO was not a suitable solvent, the porphyrin was dissolved in pyridine. The four ethyleneglycol monomethyl ether derivatives appended to porphyrin $\mathrm{Fe}$ (III)1 aids in the formation and stabilization of nanoparticles. Control experiments without PEG yielded no stable porphyrin nanoparticles. Consistent with other nanoparticle preparations, the stabilizer prevents agglomeration and is a factor in determining nanoparticle size. ${ }^{13}$

Dynamic light scattering (DLS) was used for initial characterization of the porphyrin nanoparticles, Table 1. Figure 1A shows the DLS measurement of a nanoparticle size of $\mathrm{Fe}(\mathrm{III}) \mathbf{1}$. The average particle radius is $27 \mathrm{~nm}$, and the size distribution of the nanoparticles is remarkably narrow. Since many applications of these materials require them to be on surfaces, atomic force microscopy (AFM) was used to evaluate the integrity of the nanoparticles on glass in the absence of solvent, Figure 2. The heights of the nanoparticles measured by AFM are 30-65 nm, Figure 1B, which is in general agreement with the DLS result, but this is not necessarily the case for each entry in Table 1. Consistent with other nanoparticle preparations, ${ }^{7-12}$ different water-to-acetonitrile ratios affect the size of porphyrin nanoparticles, Figure 3.

As expected, the UV-vis spectra of porphyrin nanoparticles are significantly different compared to the spectra of the corresponding porphyrin solutions. Soret bands were found to be broadened and split. Figure 4 presents the optical spectra of nanoparticles of a free base hydrophilic porphryin $\mathbf{2}$, and of its component molecule in water. The arrangement of macrocycles in aggregates generally fall into two types, "J" (edge-to-edge) and "H" (face-toface). Each type, J and $\mathrm{H}$, have distinctive spectral features that can be exploited or utilized. ${ }^{14}$ The split Soret band together with the broadened and red-shifted Q-bands in the optical spectra suggest both types of interactions in the nanoparticles. ${ }^{6,14}$ These spectra are consistent with other porphyin nanoscaled aggregates encapsulated in MCM- $41^{6}$ and are well-understood to be indicative of electronic coupling of the chromophores. ${ }^{1,4,14}$

The porphyrin nanoparticles are likely held together by hydro- phobic and $\pi$-stacking effects. ${ }^{14}$ In polar solvents such as water, these intermolecular forces become stronger, and no mater the substitution, the porphyrin core remains hydrophobic. The initial dispersion in the solvent system may contain hundreds of porphyrins $\pi$-stacked together. If the particle is more than one porphyrin wide in any dimension, as observed by DLS and AFM data, the aggregation may be cooperative-resulting in more thermodynamically stable particles than expected from the $\sim 5 \mathrm{kcal} / \mathrm{mol}$ per porphyrin face $\pi$-stacking energy. ${ }^{14}$ The porphyrin nanoparticles are exceptionally stable as judged by the unchanging optical spectrum and DLS after months of storage. 
Preliminary results on the catalytic activity of Fe porphyrin nanoparticles, $\mathrm{Fe}(\mathrm{III}) \mathbf{1}$, or $\mathrm{Fe}(\mathrm{III}) 7$ reveal that they have a $\sim 70$ - fold greater turnover number and a 10 -fold greater rate than the individual porphyrin in solution using a standard catalytic epoxidation of cyclohexene. ${ }^{15}$

In conclusion, we have developed a general method for preparation of stable $20-200 \mathrm{~nm}$ diameter porphyrin nanoparticles from a wide variety of meso-arylporphyrins. The elegance of the method lies in its simplicity. This work shows that the agent used to prevent agglomeration can be covalently attached to the dye forming the particle or as part of the solvent system. It also demonstrates that these and other types of dyes with a range of photonic properties do not need to be prepared by encapsulation in matrices or by designed self-assembly a priori. The matrix may severely limit the functionality of the particles in the former case, and at present, this size of particle is difficult to achieve in the latter. A "green" synthesis of porphyrins ${ }^{16}$ will also make these materials more economically feasible.

\section{Supplementary Material}

Refer to Web version on PubMed Central for supplementary material.

\section{Acknowledgment.}

C.M.D. thanks NSF, CHE-0135509, and the Israel-U.S. Binational Science Foundation.

\section{References}

(1). (a)See: Chou J-H; Kosal ME; Nalwa HS; Rakow NA; Suslick KS In The Porphyrin Handbook; Kadish KM, Smith KM, Guilard R, Eds.; Academic Press: New York, 2000; Vol. 6, pp 43-131(b) Chambron J-C; Heitz V; Sauvage J-P In The Porphyrin Handbook; Kadish KM, Smith KM, Guilard R, Eds.; Academic Press: New York, 2000; Vol. 6, pp 1-42.

(2). Self-assembly reviews: (a) Lehn J-M Pure Appl. Chem 1994, 66, 1961- 1966.(b) Lindsey JS New J. Chem 1991, 15, 153-180.(c) Stang PJ; Olenyuk B Acc. Chem. Res 1997, 30, 502-518.

(3). Belanger S; Hupp JT Angew. Chem., Int. Ed 1999, 38, 2222-2224.(b) Crossley MJ; Prashar JK Tetrahedron Lett 1997, 38, 6751- 6754.

(4). Drain CM; Nifiatis F; Vasenko A; Batteas JD Angew. Chem., Int. Ed 1998, 37, 2344-2347.(b) Drain CM; Lehn J-M J. Chem. Soc., Chem. Commun 1994, 2313-2315.(c) Milic TN; Chi N; Yablon DG; Flynn GW; Batteas JD; Drain CM Angew. Chem., Int. Ed 2002, 42, 2117-2119.

(5). Dagani R Chem. Eng. News 1998, 76, 70-78.(b) Dagani R Chem. Eng. News 1998, 76, 1-32.(c) Dagani R Chem. Eng. News 1999, 77, 25-37.

(6). Xu W; Guo H; Akins DL J. Phys Chem B 2001, 105, 1543-1546.

(7). Keuren EV; Georgieva E; Adrian J Nano Lett 2001, 1, 141-144.

(8). Wiese H; Horn D Ber. Bunsen-Ges. Phys. Chem 1993, 97, 1589- 1597.

(9). Debuigne F; Jeunieau L; Wiame LJ; Nagy JB Langmuir 2000,16, 7605-7611

(10). Fu HB; Yao JN J. Am. Chem. Soc 2001, 123, 1434-1439.

(11). Matsuda H; Van Keuren E; Masaki A; Yase K; Mito A; Takahashi C; Kasai H; Kamatani H; Okada S; Nakanishi H Nonlinear Opt 1995, 10, 123-128.

(12). Li M; Jiang M; Zhu L; Wu C Macromolecules 1997, 30, 2201- 2203

(13). Qi L; Colfen H; Antonietti M Nano Lett 2001, 1, 61-65.

(14). Maiti NC; Mazumdar S; Periasamy N, J. Phys. Chem. B 1998, 102, 1528-1538(b) Hunter CA; Sanders JK M. J. Am. Chem. Soc 1990, 112, 5525-5534.(c) Kano K; Minamizono H; Kitae T; Negi SJ Phys. Chem. A 1997, 101, 6118-6124.(d) Drain CM; Batteas JD; Flynn GW; Milic T;

J Am Chem Soc. Author manuscript; available in PMC 2018 November 13. 
Chi N; Yablon DG; Sommers H Proc. Natl. Acad. Sci. U.S.A 2002, 99, 6498-6502. [PubMed: 11880598] (e) Purrello R; Monsu' Scolaro L; Bellacchio E; Gurrieri S; Romeo A Inorg. Chem 1998, 37, 3647-3648. [PubMed: 11670458]

(15). Groves JT; Nemo TE J. Am. Chem. Soc 1983, 105, 5786-5791.

(16). Drain CM; Gong X Chem. Commun 1997, 2117-2118.JA027405Z 

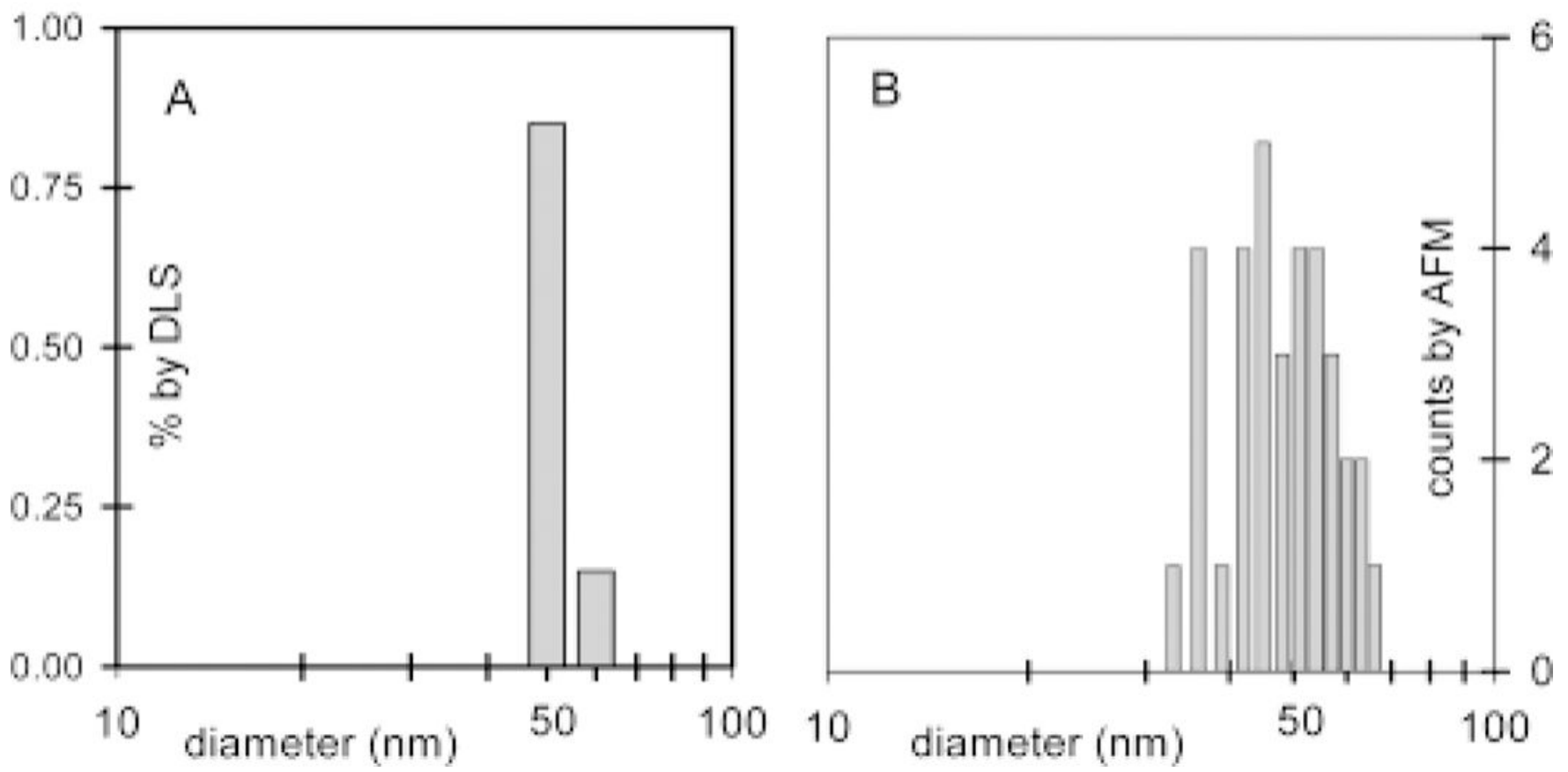

Figure 1.

(A) DLS characterization of porphyrin nanoparticles, average diameter $=54 \mathrm{~nm}$, made by adding $5 \mathrm{~mL}$ of acetonitrile to a solution containing $0.6 \mathrm{mg}$ of $\mathrm{Fe}(\mathrm{III}) \mathbf{1}$ in $0.035 \mathrm{~mL}$ of water.

(B) Height distributions determined by AFM of the same solution see Figure 2. 


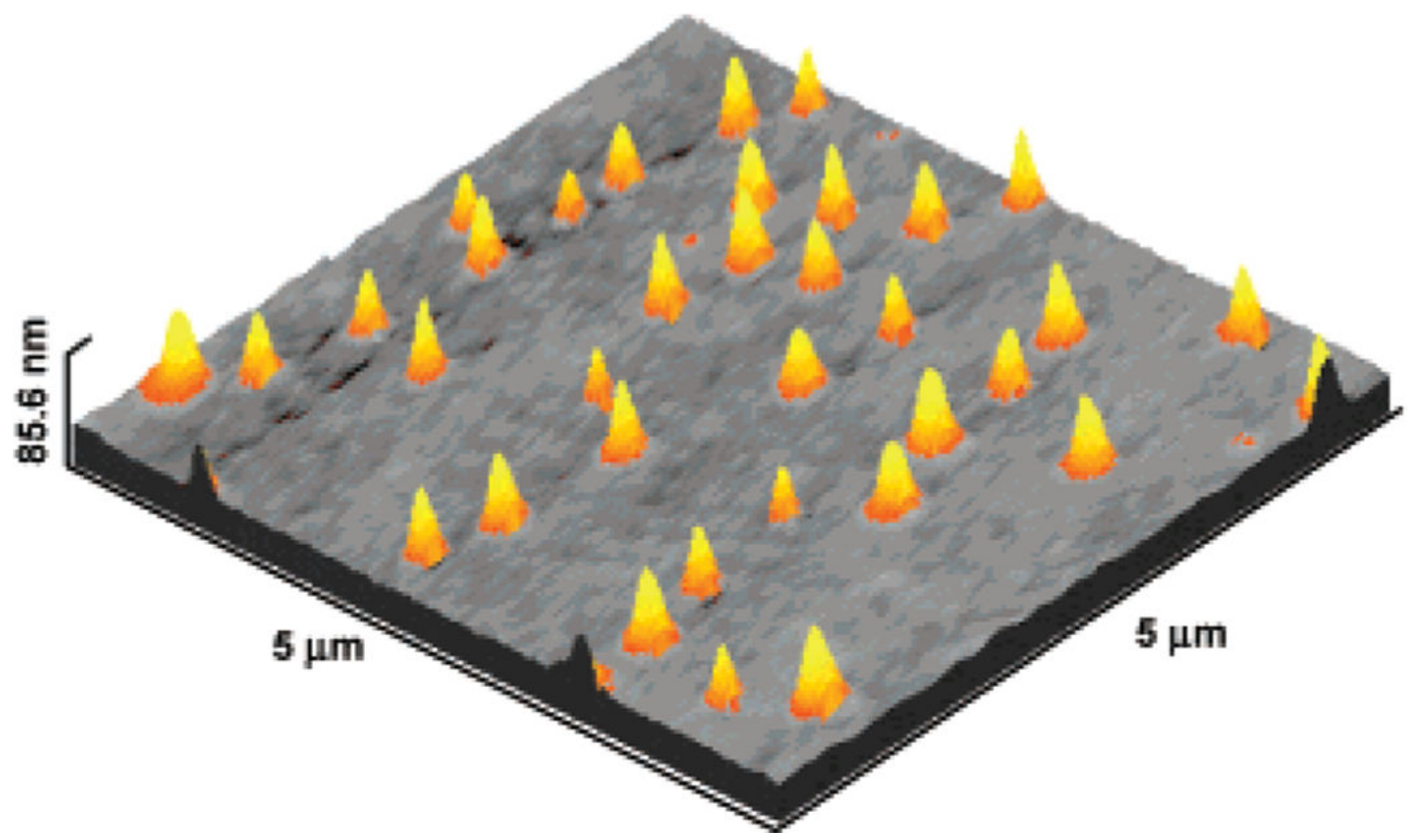

Figure 2.

Topographic AFM image of porphyrin nanoparticles of Fe(III)1 on glass. The particles are from the same solution as that used in the DLS measurement. 


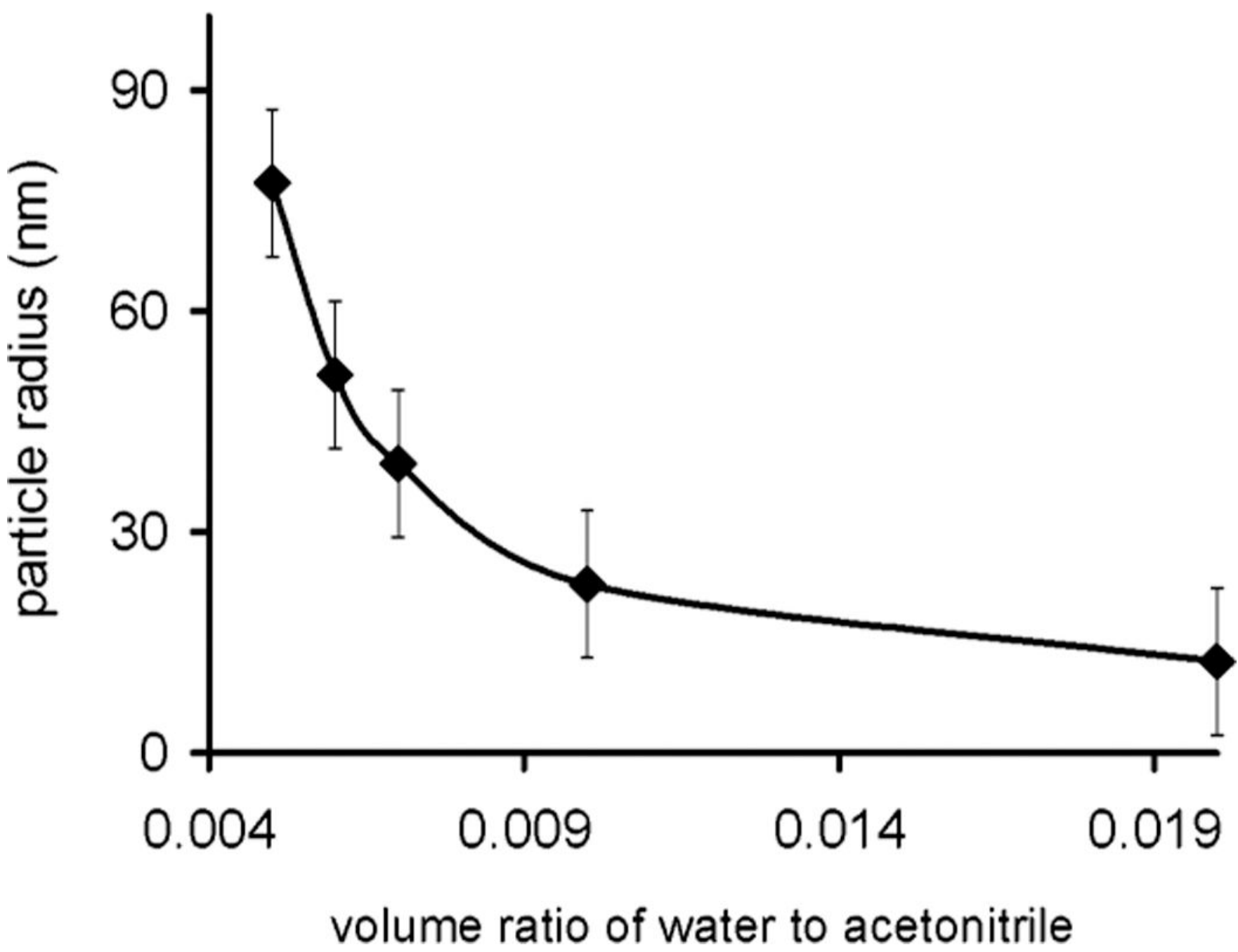

Figure 3.

Relationship between particle radius of porphyrin $\mathrm{Fe}(\mathrm{III}) \mathbf{1}$ and water content of solvent determined by DLS; the error bars represent the distributions. 


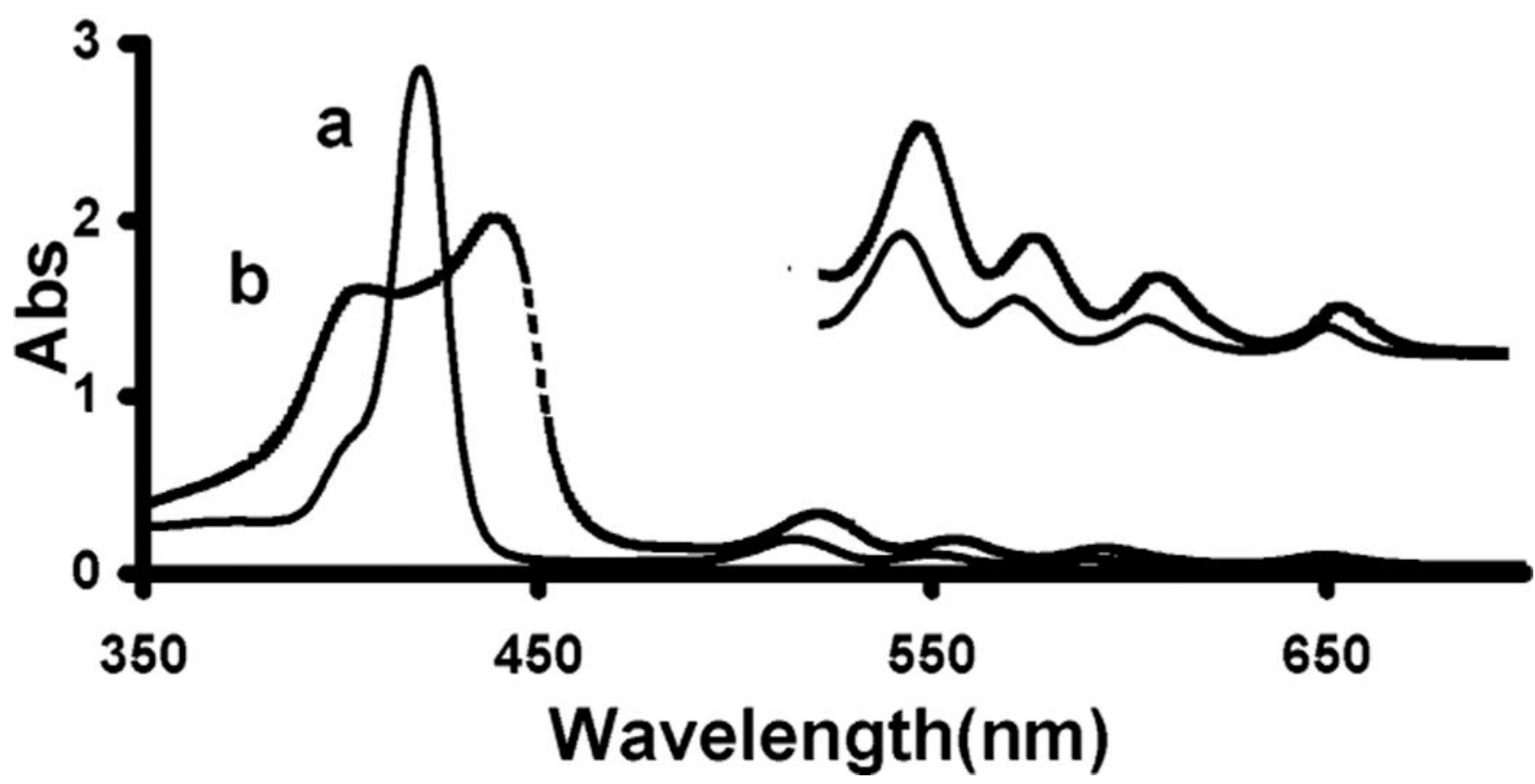

Figure 4.

UV-vis spectra, $2 \mathrm{H} 2$ in DMSO (a) and its nanoparticle in water (b). The inset absorbance scale is $\times 5$. 
Table 1.

Hydrodynamic Radii of Nanoparticles Formed from Hydrophobic, Hydrophilic, Amphipathic, and Bisfunctionalized Porphyrins, by DLS; = Represents the Distributions

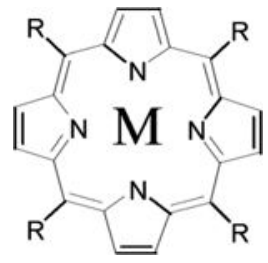

\begin{tabular}{llll}
\hline $\mathbf{R}$ & $\mathbf{M}$ & $\begin{array}{l}\text { Average radius } \\
(\mathbf{n m})\end{array}$ \\
\hline 1 & & $\mathrm{Fe}(\mathrm{III})$ & $27( \pm 6)$ \\
& &
\end{tabular}

\begin{tabular}{llll}
2 & 4-carboxylpheny1 & $2 \mathrm{H}^{+}$ & $46( \pm 40)$ \\
$\mathbf{3}$ & 4-carboxylpheny1, methy1 ester & $2 \mathrm{H}^{+}$ & $58( \pm 47)$ \\
$\mathbf{4}$ & Pheny1 & $2 \mathrm{H}^{+}$ & $11( \pm 4)$ \\
$\mathbf{5}$ & 4-methoxypheny1 & $2 \mathrm{H}^{+}$ & $34( \pm 30)$ \\
$\mathbf{6}$ & 4-pyridy1 & $2 \mathrm{H}^{+}$ & $70( \pm 50)$ \\
$\mathbf{7}$ & 5,15 -(mesity1)-10,20-(4-bromo-pheny1) & $2 \mathrm{H}^{+}$ & $24( \pm 6)$ \\
\hline
\end{tabular}

3 4-carboxylpheny1, methy1 ester

$58( \pm 47)$ 